\title{
Prospective therapeutic microbiome engineering and human metagenome manipulation: A mini review
}

\author{
Muhammad Asghar ${ }^{1}$, Jangrez Khan ${ }^{2}$, Haider Khan ${ }^{3}$ and Rabia Bibi ${ }^{1 *}$ \\ 1. Department of Molecular Biology, Virtual University of Pakistan \\ 2. Quaid I Azam University, Islamabad, Pakistan \\ 3. Chonnam National University, Gwangju, South Korea \\ *Corresponding author's email: rabiyahh786@gmail.com
}

Citation

Muhammad Asghar, Jangrez Khan, Haider Khan, Rabia Bibi. Prospective therapeutic strategies of microbiome engineering and human metagenome manipulation: A mini review. Pure and Applied Biology. Vol. 11, Issue 3, pp684695. http://dx.doi.org/10.19045/bspab.2022.110069

\begin{tabular}{llll}
\hline \hline Received: 29/07/2021 & Revised: 20/09/2021 & Accepted: 23/09/2021 & Online First: 07/10/2021 \\
\hline \hline
\end{tabular}

\section{Abstract}

Gut microbiota is a complex ecosystem with a unique diversity of microorganisms living in the digestive tracts of humans and animals and has a strong impact on human health. This microbial relationship plays a crucial role in the metabolic health of the human host. Any dysbiosis in this relationship causes various metabolic, immunological, neoplastic, and functional diseases. For the proper maintenance of relationships between gut microbiota, health, and disease, a few strategies including the use of probiotics/prebiotics, antibiotics, fecal microbial transplant, and drug targeting have been used. Gut microbiota management strategies in balance with dietary modifications signify an interesting field of research, however, associated data along with a deeper understanding is mandatory for the improvement of more targeted and specified therapeutic strategies. In this review, we will address the exciting potential, emerging challenges, and current directions in human microbiome engineering strategies. Additionally, this review analyzes the significance and use of microbiome engineering for the improvement of human health.

Keywords: Antibiotics; Diet; Gut microbiota; Prebiotics; Probiotics; Microorganisms

\section{Introduction}

Microorganisms existing in the digestive tract of humans, animals, and insects form a complex community, and the collective aggregate of their genome forms the gut metagenome [1]. Human microbiota resides in human tissues, bio-fluids, oral mucosa, saliva, gastrointestinal (GI) tracts, skin, mammary glands, uterus, placenta, seminal fluid, lungs, etc. [2]. Among microbial groups, the gut flora is regarded as most important to the host as $\sim 100$ trillion $\left(10^{14}\right)$ microorganisms residing in the GI tract hold
150 times as many genes as the human genome. There is a strong symbiotic relationship between gut microbes and humans in which a continuous source of nutrition is supplied by humans; in return, gut microbes provide various health benefits [3]. It has been estimated that the human microbiome is composed of more than 5000 strains of microbes and more than 1000 types of microflora. Principally this environment is dominated by anaerobic bacteria however, others include viruses, protozoans, archaea, and fungi. The microbiome is primarily 
defined by two bacterial phylotypes; Bacteroidetes and Firmicutes, whereas a relatively small amount of Actinomyces, Proteobacteria, Fusobacterium, and Verrucomicrobia also exist. The composition of gut flora varies with human development and is affected by several factors including host genetics, age, nutrition, antibiotic usage, and mode of birth. Babies receive the initial microbiome from their mothers and after 1 year; the newborns form their own complex gut microbiome like adults [4]. There is a strong balance in the enteric microbiota that deliberates health assistance and contributes to maintaining the homeostasis further ensuring human health and safety [5]. Gut flora helps us in proper food digestion, activation of certain drugs, production of short-chain fatty acids (SCFAs) that help in the modulation of gene expression, generation of molecules that decrease inflammation, and plays a vital role in the initiation, growth, training, and functioning of the immune system. Conversely, dysbacteriosis of healthy gut microbiota results in the drop of this mutualistic association and causes many ailments like obesity, metabolic syndrome, diabetes (Type I, II), inflammatory bowel disease (IBD), irritable bowel syndrome, colorectal cancer, celiac disease, and a wide range of mental and neurological disorders $[6,7]$. Thus, there is a strong need to comprehend the microbiome and advance understandings into elements that further add to differences in microbiomes. In this review, we have analyzed the significance and use of microbiome engineering, predominantly for the improvement of human health, and exploring the challenges and forthcoming human microbiome engineering strategies.

\section{Dietary effects on gut microbiota}

Diet is one of the major factors driving the configuration, conformation, and metabolism of the gut microbiota. The total sum, variety, and equilibrium of the key dietary macronutrients (proteins, carbohydrates, and fats) have an excessive influence on the large intestinal microbiota [8]. Since the 1960s, there is a heated debate among the scientific community on the prospects that diet may affect the gut microbiota. Experiments have shown that when germ-free mice were subjected to a high-fat and high-sugar western diet, changes occurred in the structure of the intestinal microbial community with increased numbers of members of the phylum Firmicutes and decreased profusion of phylum Bacteroidetes [9]. Also, intestinal microbiota can change and remodel its composition swiftly by deviation in the diet for a short time. To observe the differences and reproducibility in gut microbiota, animal and plant-based diets were given to 10 American volunteers (between the age of 21 and 33). During animal-based diet consumption, the richness of bile tolerant microorganisms such as Alistipes, Bilophila, and Bacteroides increased, whereas a decrease was noted in the profusion of Firmicutes involved in processing nutritive plant polysaccharides (Roseburia, Eubacterium rectale and Ruminococcus bromii). On the other hand, short-term dietary forms persisted ineffectually in producing major variations in 'enterotypes', that are distinct as three groups of genera subjugated by Bacteroides, Prevotella, and Ruminococcus [10]. Thus, the ability of human gut microflora to rapidly change their composition and functionalities can be directly associated with the evolution of human beings with respect to the unavailability of some food sources over time. In past, humans were dependent on the attainment of hunting for animal-based diets, while additional plant-based nutrient consumption was more common, so these quick variations in nutrition improved the selective pressure for increasing the flexibility of functional components of the gut microbiota [11, 12]. Recently, mouse 
model studies suggested that due to modern animal-based diet patterns, the bile acid biosynthesis mechanism is facing critical alterations in which high production of bile acid known as deoxycholic acid occurs. Consequently, it results in stimulating liver cancer. It has also been observed that high fat/ animal-based diets may promote the growth and development of Bilophila wadsworthia (a gram-negative sulphitereducing bacteria), which is one of the signals for triggering IBD. In another clinical study, when a fat-rich and western-style diet was given to healthy individuals, increased plasma endotoxin levels were observed in comparison with individuals who were on an isocaloric steady diet. This can be a result of a disturbance in the gut microbiota [13]. On the other hand, plant-derived diets have a high fiber content than animal-derived diets. Thus, bacterial fermentation of nutritional polysaccharides can deliver $10 \%$ of the energy consumption which can stimulate deviations in the gut microbiota to perform numerous favorable functions including defense from inflammation, cardiac diseases, obesity, diabetes, and high blood pressure [10]. A comparative study [14] showed the effect of diet on host physiology by converting the plant polysaccharides-rich diet (low-fat) to an animal based, high-sugar diet (high-fat) in germ-free mice colonized with a human gut microflora. Results confirmed that due to dietary changes, gene expression patterns and metabolic pathways of the microbiome changed within a day. Diet having fiber enrichment caused plenty of Bacteroidetes and decreased the richness of Firmicutes [15].

Various nutrients like vitamins, fats, amino acids, or nutritional fiber consumed by the host are assimilated and transformed into supplementary metabolites by intestinal microflora. Certain yields of these biochemical reactions, such as SCFAs, biogenic amines or additional amino-acid- derived metabolites such as serotonin (a neurotransmitter) or gamma-aminobutyric acid (GABA), could be naturally active in health and disease conditions. Production of such complexes also induces variations in microbial composition. Due to the fermentation of dietary non-digestible carbohydrates in the intestinal lumen, SCFAs such as acetate, propionate and butyrate can be produced. These metabolically active SCFAs are involved in various biological mechanisms providing metabolic energy bases for human colonic epithelial cells (Fig. 1).

Currently, the main emphasis of microbiome understanding is primarily on the management and preclusion of dysbacteriosis (dysbiosis) and related conditions. Due to lack of complete knowledge, it has not been utilized to its complete perspective and huge section of human microbiota is still to be discovered. However, it is expected that in near future, the finding of leading and exceptional members of microbial groups serving explicit constructive functions is possible to link this breach and might become the backbone of bacteriotherapy for numerous disorders. Microbiome engineering will not only broaden this possibility to meet pre-emptive and therapeutic but also the investigative prerequisites [16].

Most of the major diseases including obesity, colon cancer, diabetes, and inflammatory bowel disease have all been associated with fluctuations in the composition of the human gut microbiome. For the proper understanding, detection, and therapeutic treatment of gut dysbiosis, we require more cultured and refined tackles like microbiome engineering and transplantation. To control the configuration and functional aspects of the microbiome, great efforts have been made including the introduction of new members to the community by using probiotics and fecal transplantation, such as elimination of 
unwanted members by using antibiotics and intestinal lavage methodologies. Still, these approaches are nonspecific and frequently result in unpredictable and random endings [17]. Recently, many therapeutic and targeted therapies have been employed to get more specific results. We will address the major ones including prebiotics, probiotics, dietary emulsifiers, fecal microbial transplants, antibiotics, and synthetic microbes.

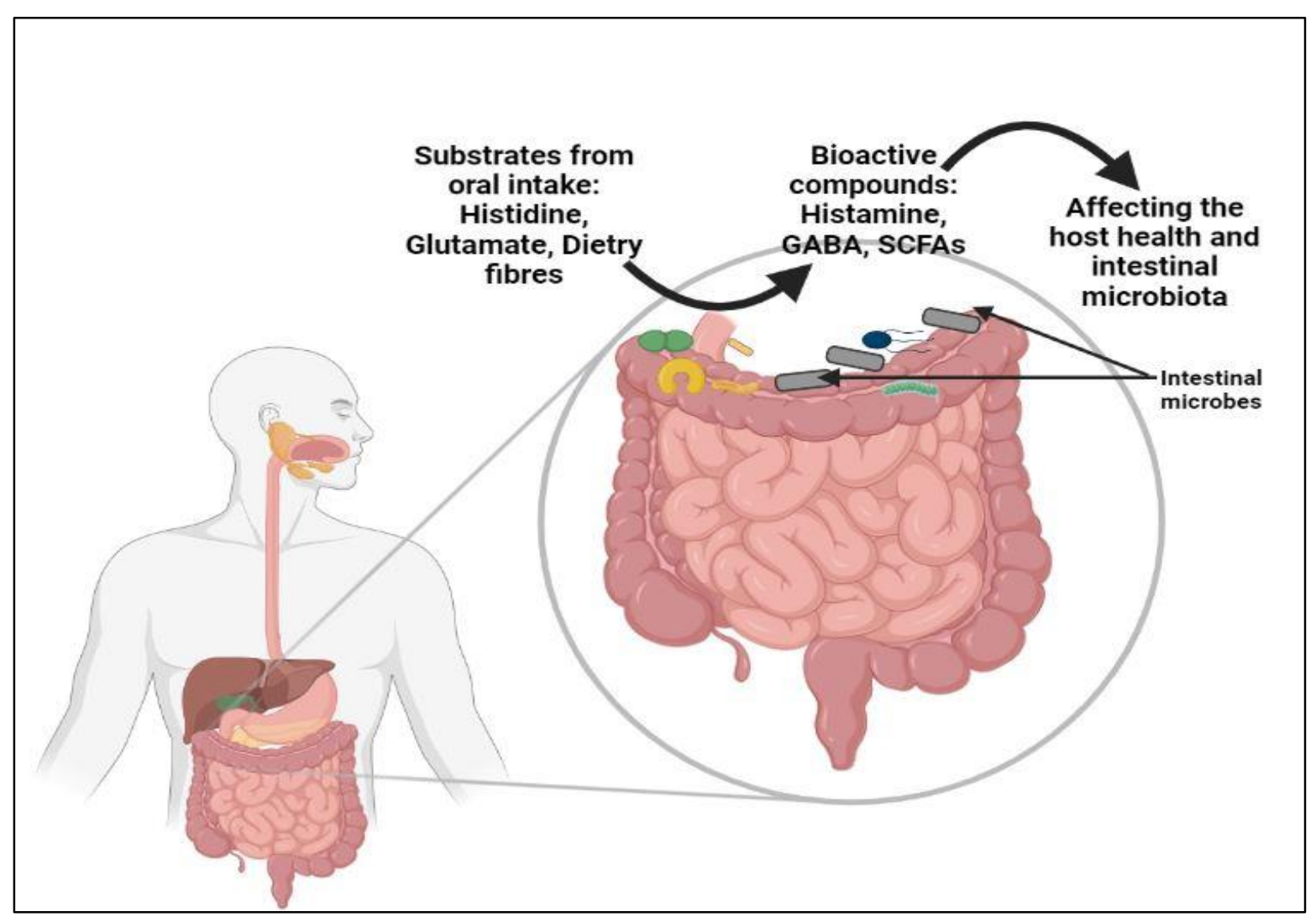

Figure 1. Intestinal microbial communities cause changes in human health status and different disease states.

Restoring microbiota through prebiotics, probiotics, and dietary emulsifiers

Non-viable dietary compounds (usually nondigestible fiber compounds) such as insulin, oligofructose, and gluco-oligosaccharides that deliberate health benefits on the host accompanying with modulation of microbiota are known as prebiotics [18]. Research shows that administration of prebiotics results in improved production of SCFAs that act as a as nutrition for colonic walls, and moderation of ulcerative colitis indications thus beneficial to inflammatory bowel disease or Crohn's disease [19, 20]. Fermentable oligosaccharides (e.g., fructans) also called fermentable oligosaccharides, disaccharides, monosaccharides, and polyols (FODMAPs), are poorly absorbed materials. They have been shown to affect irritable bowel syndrome symptoms thus, restriction of foods containing FODMAPs have been sightseen as a prospective therapeutic intervention [21].

Probiotics are microbes (bacteria or yeast) that provide health aids when consumed and are called as good or helpful bacteria as they keep the gut healthy. The mechanism of action of probiotics is; if the body loses good bacteria or dysbiosis occurs, they help to replace them effectively further treating a 
wide range of gastrointestinal diseases. Most of the recommended probiotics come from two groups: Lactobacillus and Bifidobacterium animalis [22]. Recent studies have shown that probiotic bacteria adjust the settlement and eradication of pathogens in the gut, and modulate the mucosal immune system [23, 24]. Probiotics are regarded as a significant prophylactic or therapeutic approach for several mucosal and non-mucosal immune-related disorders, such as IBDs, celiac disease, metabolic syndrome, and diabetes [25]. Probiotics have been fruitfully employed for the treatment of antibiotic-associated diarrhea and have antimicrobial, antimutagenic, anti-diarrheal, and anticarcinogenic properties. They have the potential to show progress in lactose metabolism, drop of serum cholesterol levels, immune system stimulation, and decrease of Helicobacter pylori infection [26]. The clinical effectiveness and ability of probiotics and prebiotics have been demonstrated in several clinical settings thus blend of prebiotics with probiotic bacteria has the potential to change gastrointestinal flora for the gain of thoroughgoing health benefits [27].

Dietary emulsifiers cause intestinal inflammation, metabolic syndrome, and inflammatory bowel diseases; apart from that, they are also involved in the prevalence rate of these disorders. Carboxymethylcellulose and polysorbate 80 are two synthetic emulsifiers that affect the intestinal microbiota and are known to cause bacterial translocation across the intestinal epithelium. The dietary emulsifiers tested in a mini bioreactor arrays model proved adverse effects on human intestinal microbiota [28]. Some food additives, too, are being used frequently but their impacts on human microbiota are still to be investigated. It is further indicated that clinical trials are required to test whether emulsifying agents have little or no effect on microbiota, so that, the usage of detrimental compounds might be reduced.

\section{Fecal microbiota transplant (FMT)}

The technique used for the restoration of gut microbiota back to their normal density and diversity to attain proper gut functionality is called fecal microbiota transplant or stool transplant [29]. In this process, beneficial intestinal bacterial and yeast strains are taken from a healthy donor and implanted into the colon of a person who is missing the essential gut microflora due to having a functionally improper digestive system. FMT may prove effective and an operative strategy for the treatment of IBD and Clostridium difficile infection for which some early trials have shown success. A case study has shown the cure rate of $80-90 \%$ via FMT with no stern adverse procedures in the short term. The four main types of fecal transplants used in human medicine are mentioned in (Table 1) [30].

In the last 5 years, FMT has gained the consideration of physicians, consultants, and the US Food and Drug Administration (FDA). Fecal matter, if used to modify the physiology of a receiver, meets the federal definition of a drug, and consequently falls under the FDA's monitoring remit [31, 32]. FMT has been tested in the treatment and management of many diseases, including metabolic disorders, autoimmune and hypersensitive diseases, neurodevelopmental and neurodegenerative conditions, prolonged fatigue syndrome, etc. Recent studies have shown that microbiomes of super-donors are greatly effective in fecal microbiota transplant. It was observed that administration of FMT capsules from multiple donors resulted in continuous alterations in the structure and function of the gut microbiome. Promising results have been shown in many reports, though they are dealing with a very little number of patients and supplementary well-designed, randomized well-ordered trials are 
compulsory for the establishment of the effectiveness of FMT for these ailments. Additionally, FMT studies have an inherent limitation due to the variability of individual's stool composition [30, 33, 34].

Table 1. Types of fecal transplantation

\begin{tabular}{|c|c|c|}
\hline Type & Requirements & Advantages/ Drawbacks \\
\hline $\begin{array}{c}\text { Single donor fecal } \\
\text { transplantation }\end{array}$ & $\begin{array}{c}\text { Single recipient is required (donor should be } \\
\text { close relative or friend). } \\
\text { Donor should be tested for the absence of } \\
\text { pathogenic bacteria and particular diseases. } \\
\text { Donor must be tested for the absence of } \\
\text { pathogens and specific diseases. }\end{array}$ & $\begin{array}{c}\text { Long delayed and often } \\
\text { costly. }\end{array}$ \\
\hline $\begin{array}{c}\text { Multiple } \\
\text { donors' fecal } \\
\text { transplantation }\end{array}$ & $\begin{array}{c}\text { Donor should be tested for the absence of } \\
\text { pathogenic bacteria and particular diseases. } \\
\text { Stool banks should be established. }\end{array}$ & $\begin{array}{c}\text { No published microbiome } \\
\text { and metabolomic data till yet. }\end{array}$ \\
\hline $\begin{array}{c}\text { Autologous feces } \\
\text { transplantation }\end{array}$ & $\begin{array}{c}\text { Collection of fecal samples before therapeutic } \\
\text { involvements and proper storage. }\end{array}$ & $\begin{array}{c}\text { No published microbiome } \\
\text { and metabolomic data till yet. }\end{array}$ \\
\hline $\begin{array}{c}\text { Anaerobically } \\
\text { cultivated fecal } \\
\text { transplantation }\end{array}$ & $\begin{array}{c}\text { Donor's selection and pathogen screening is only } \\
\text { necessary once. }\end{array}$ & Best and cheapest method \\
\hline
\end{tabular}

\section{Administration of antibiotics}

Many strategies can be employed to alter the human gut microbiome. Animal model studies have shown that various antimicrobial peptides, like thuricin Clostridium difficile (thuricin CD) and pyocin S5 were used for narrow spectrum targeting of pathogenic bacteria. This resulted in the reduction of the chance of resistance and disturbance to the gut microbiota [35]. The results provided the possibility of developing a very effective targeted methodology for removing $C$. difficile in the colon, without collateral impairment [36]. It has been observed that the composition, taxonomic richness, diversity, and evenness of gut microbiota can be altered by the administration of broadspectrum antibiotics. Antibiotics cannot only change the composition of taxa but also affect the expression level of genes, protein activity, and whole metabolism of the gut microbiota. Ex vivo incubations of fecal samples with various antibiotics have shown an increased percentage of gut microbiota cells with damaged and impaired membranes. This means that there is a change in the active populations of the microbiota, antibiotic resistance genes, stress response and amplified expression in phage induction $[37,38]$. However, one of the major threats of excessively widespread use of antibiotics is increased resistance of bacterial pathogens to antibiotics that is becoming a global challenge. The (Table 2) shows that how a simple antibiotic course will cause turbulence in the composition of gut microbiota [39].

Synthetic microbes as drug delivery systems

Studies have shown that some diseases of the GI tract could be treated by orally administrating a synthetic bacterium that can crisscross to the preferred location, engraft, and start supplying a drug. From engineered microbes, the recombinant expression of therapeutic biomolecules can help resolve an infection, stop inflammation, and treat metabolic conditions. This method is useful for protein containing compounds as they cannot pass through an acidic stomach environment in addition to the cost-effective method [17, 47]. It has been reported that genetically engineered Lactobacillus jensenii 
stopped the spread of chimeric simian/human immunodeficiency virus (SHIV) in a rhesus macaque monkey model. Lactobacillus jensenii was engineered to express an antiviral molecule (cyanovirin-N) and it not only reduced the incidence of SHIV but also the ultimate viral contents when directed as a prophylactic treatment $[31,48]$.

Metabolic diseases like obesity and diabetes are also being addressed successfully by drug delivery systems. A previous study reported that obesity was reduced in mice by the introduction of genetically engineered $E$. coli expressing therapeutic factors in gut microbiota. It was shown that administration of engineered NAPE-expressing $E$. coli Nissle 1917 bacteria in drinking water for 8 weeks successfully resulted in reduced levels of obesity even fed with a high-fat diet [49].
Another condition known as hyperammonemia (in which an excessive amount of ammonia gathers systemically thus causing neurotoxicity and encephalopathy in individuals having a liver disease) can be recovered through microbial engineering. In mouse model studies, it has been observed that community-wide urea metabolism can be altered by using genetically modified gut microflora. In these studies, the existing endogenous microbiota were depleted out and a well-defined microbial community displaying low urease activity were transplanted which resulted in continuously stable urease levels [31]. The (Table 3) shows detailed results of microbiome engineering for different diseases, as modified from [16].

Table 2. Summary of research on the influence of antibiotics on the human intestinal microbiota

\begin{tabular}{|c|c|c|c|}
\hline \multirow{2}{*}{$\begin{array}{l}\text { Antibiotic } \\
\text { regime }\end{array}$} & \multirow{2}{*}{ Subjects } & Short term results & \multirow{2}{*}{ Ref. } \\
\hline & & long term results & \\
\hline \multirow[t]{2}{*}{$\begin{array}{l}5 \text { days orally } \\
\text { Amoxicillin }\end{array}$} & \multirow[t]{2}{*}{$\begin{array}{l}6 \text { (adult healthy } \\
\text { volunteers) }\end{array}$} & $\begin{array}{l}\text { After } 24 \text { hours, alteration in dominant species occurred. } \\
\text { After } 4 \text { days: } 74 \% \text { average similarity as compared to pre- } \\
\text { treatment. }\end{array}$ & \multirow[t]{2}{*}[40]{} \\
\hline & & $88-89 \%$ similarity in $1-2$ months. & \\
\hline \multirow[t]{2}{*}{ Amoxicillin } & \multirow{2}{*}{$\begin{array}{l}28 \\
\text { (young pediatric } \\
\text { patients) }\end{array}$} & $\begin{array}{c}\text { Decreased number of Bifidobacteria and B. fragilis species } \\
\text { compared to non-treated kids. }\end{array}$ & \multirow[t]{2}{*}{ [41] } \\
\hline & & No changes reported & \\
\hline \multirow{2}{*}{$\begin{array}{l}\text { Orally } 7 \text { days } \\
\text { Clindamycin }\end{array}$} & \multirow{2}{*}{$\begin{array}{l}4 \text { healthy adults/ } \\
4 \text { controls }\end{array}$} & Day 7, 21: large and consistent shift in composition. & \multirow[b]{2}{*}{ [42] } \\
\hline & & $\begin{array}{c}3,6,9,12,18 \text { and } 24 \text { months: large and constant shift in } \\
\text { composition }\end{array}$ & \\
\hline \multirow{2}{*}{$\begin{array}{l}\text { Orally } 5 \text { days } \\
\text { Ciprofloxacin }\end{array}$} & \multirow[t]{2}{*}{3 healthy adults } & $\begin{array}{l}\text { In the gut affected ones, abundance of the bacterial taxa; } \\
\text { reduced taxonomic richness, multiplicity, and uniformity of } \\
\text { the community. }\end{array}$ & \multirow[t]{2}{*}{ [43] } \\
\hline & & $\begin{array}{l}1 \text { and } 6 \text { months: productivity, diversity, and constancy } \\
\text { comparable to pre-antibiotic state, certain long-term losses. }\end{array}$ & \\
\hline \multirow{2}{*}{$\begin{array}{l}\text { Metronidazole } \\
\stackrel{+}{\text { Orally } 7 \text { days }} \\
\text { clarithromycin }\end{array}$} & \multirow{2}{*}{$\begin{array}{l}3 \text { Healthy adults } \\
+3 \text { controls }\end{array}$} & $\begin{array}{c}\text { Intense reduction in diversity, specifically loss of } \\
\text { Actinobacteria, in both throat and feces. }\end{array}$ & \multirow{2}{*}{ [44] } \\
\hline & & 1 year: diversity levels recovered to pretreatment states & \\
\hline \multirow{2}{*}{$\begin{array}{l}\text { Ampicillin } \\
\text { and } \\
\text { gentamicin } \\
\text { (within } 48 \mathrm{~h} \\
\text { of }\end{array}$} & \multirow{2}{*}{$\begin{array}{l}9 \text { pediatric } \\
\text { Patients }+9 \\
\text { untreated } \\
\text { infants }\end{array}$} & $\begin{array}{l}4 \text { weeks (after treatment): antibiotic-treated newborns had } \\
\text { greater amounts of Proteobacteria and lower amounts of } \\
\text { Actinobacteria along with genus Lactobacillus. }\end{array}$ & \multirow[t]{2}{*}{ [45] } \\
\hline & & $\begin{array}{c}2 \text { months: Higher levels of Proteobacteria but recovered } \\
\text { levels of Actinobacteria and Lactobacillus. }\end{array}$ & \\
\hline
\end{tabular}




\begin{tabular}{|c|c|c|c|}
\hline Birth) & & \\
\hline $\begin{array}{c}\text { Oral } \\
\text { administration } \\
\text { of broad- } \\
\text { spectrum } \\
\text { antibiotics }\end{array}$ & 21 adult patients & $\begin{array}{c}\text { 25\% reduced microbial diversity was observed by treatment } \\
\text { with Fluoroquinolones and b-lactams; Increased percentage } \\
\text { of Bacteroidetes taxa; average microbial load was increased } \\
\text { roughly two-fold by B-lactams. }\end{array}$ & [46] \\
\cline { 2 - 3 } & & None reported & \\
\hline
\end{tabular}

Table 3. Engineered microflora

\begin{tabular}{|c|c|c|}
\hline $\begin{array}{l}\text { Engineered } \\
\text { commensal } \\
\text { microflora } \\
\end{array}$ & Induced modification and result & Ref. \\
\hline $\begin{array}{c}\text { Bifidobacterium } \\
\text { longum }\end{array}$ & $\begin{array}{l}\text { In mice, recombinant Salmonella flagellin's expression on the cell surface } \\
\text { provided defense against infection from Salmonella typhimurium. }\end{array}$ & [50] \\
\hline $\begin{array}{l}\text { Lactobacillus } \\
\text { casei }\end{array}$ & $\begin{array}{c}\text { In mice, expression of protein C (pneumococci) resulted in its reduced } \\
\text { nasopharyngeal colonization. }\end{array}$ & [51] \\
\hline Lactobacillus & $\begin{array}{l}\text { Oral administration of engineered human commensal bacteria engineered } \\
\text { improved hyperglycemic condition in diabetic mouse models by } \\
\text { reprogramming intestine cells into glucose-responsive insulin-secreting cells. }\end{array}$ & [52] \\
\hline $\begin{array}{l}\text { Lactobacillus } \\
\text { jenseni }\end{array}$ & $\begin{array}{c}\text { In monkeys, colonization of vaginal mucosal cells and secretion of } \\
\text { cyanovirin-N provided defense against simian human immunodeficiency } \\
\text { virus (HIV) infection. }\end{array}$ & [53] \\
\hline $\begin{array}{l}\text { Caulobacter } \\
\text { crescentus }\end{array}$ & Display of anti-HIV antibodies resulted in neutralization of HIV. & [54] \\
\hline L. jensenii & $\begin{array}{c}\text { Anti-HIV; chemokine [Regulated upon Activation, Normal T Cell Expressed } \\
\text { and Presumably Secreted (RANTES)] and C1C5 (RANTES) expression } \\
\text { resulted in the reticence of HIV infection in CD4 }{ }^{+} \text {T cells and phagocytic } \\
\text { cells. }\end{array}$ & [55] \\
\hline \multirow{3}{*}{ E. coli } & $\begin{array}{l}\text { Production of AI-2 (autoinducer-2) and CAI-1 (cholera autoinducer 1) in } \\
\text { high concentration resulted in suppression of cholera toxin assembly by } V \text {. } \\
\text { cholerae. }\end{array}$ & [56] \\
\hline & $\begin{array}{l}\text { Engineered E.coli commensals bounded precisely to the HSPGs (heparan } \\
\text { sulphate proteoglycan) on colorectal cancer cells and secreted the } \\
\text { myrosinase and transformed host-ingested glucosinolates, thus engineered } \\
\text { microbes attached with glucosinolates resulted in more than } 95 \% \\
\text { inhibition of murine, human and colorectal adenocarcinoma cell and cell } \\
\text { line proliferation in vitro. }\end{array}$ & [57] \\
\hline & $\begin{array}{c}\text { Chimeric cell wall lipoglycans copying GM } 1 \text { ganglioside finally deactivated } \\
\text { cholera toxin and heat-labile enterotoxin of } E \text {. coli }\end{array}$ & $\begin{array}{l}58, \\
59]\end{array}$ \\
\hline $\begin{array}{l}\text { Lactobacillus } \\
\text { paracasei }\end{array}$ & $\begin{array}{l}\text { Expression of adhesion protein of recombinant Listeria resulted in } \\
\text { competitive inhibition of Listeria monocytogenes to bind with its receptor. }\end{array}$ & {$[60]$} \\
\hline $\begin{array}{l}\text { Lactococcus } \\
\quad \text { lactis }\end{array}$ & $\begin{array}{l}\text { Expression of surface-associated flagellin of Bacillus cereus } \mathrm{CH} \text { strain } \\
\text { resulted in competitive inhibition of adhesion of intestinal pathogens like } \\
\text { Salmonella enterica. }\end{array}$ & [61] \\
\hline
\end{tabular}

\section{Future perspective}

Evidence recommends that treatment with probiotics, prebiotics, antibiotics, dietary modification, FMT or drug targeting would expressively alter the comparative amount of the gut bacterial species and can result in 
the improvement of several metabolic and neurological diseases. Besides this, an adaptation of the GI microbiota may have intense metabolic penalties and concerns too. Whatsoever the method used, alteration and reformation of the gut microbiota is risky thus limitations are always there in our capability to freely examine the intestinal microbial setting in situ. There is a strong need and gap in our understanding of the interaction between gut microbiota and human health in the normal and diseased state. Only then, any effective strategy separately or combined with other methodologies can be applied to cure the disease. As up-to-date molecular methods like sequencing tools are approving the identification of various microbial species present in human GI tracts, so it's an opening to identify and categorize the types of genes that they keep. Enhanced consideration of how these genes respond to bacterial signals that affect human physiology and precise editing technologies will provide open access to the development and improvement of new treatment models. Sensibly targeted antibiotics and microbiome editing technology have the potential to remove or suppress the selected constituents and mechanisms of the human microbiome further encouraging the proliferation of advantageous microbes to exploit sustainable fluctuations in the human microbiome. Though it is evident that enormous potential subsists for manipulation of the human gut microbiota for therapeutic consequence, it is manifested that a combination of scientific methodologies, new tools, and approaches with more investigation and exploration are desired to realistically target microbedirected treatments, prevention, and management conferring to the disease state.

\section{Author's contributions}

Contributions in writing the main draft of the manuscript: $M$ Asghar \& J Khan,
Contributed to editing and proofreading the manuscript: H Khan \& R Bibi.

\section{References}

1. Saxena R \& Sharma V (2016). A Metagenomic Insight into the Human Microbiome. Med Health Genomics 107119.

2. Willey J, Sherwood L, Woolverton C \& Prescott L (2013). Prescott's microbiology. 9th Ed. (New York: McGraw-Hill Education). pp. 713-721.

3. Kavvadia M, Santis GL, Alwardat N, Bigioni G, Carmen, Zeppieri, Cascapera S \& Lorenzo A.D (2017). Psychobiotics as Integrative Therapy for Neuropsychiatric Disorders with Special Emphasis on the Microbiota-Gut-Brain Axis. Biomed Prev 2(8).

4. Wang $\mathrm{H}$ \& Wang $\mathrm{Y}$ (2016). Gut Microbiota-brain Axis. Chinese Med J Peking 129(19): 2373-2380.

5. Nguyen TTB, Jin YY, Chung HJ, \& Hong ST (2017). Pharmabiotics as an Emerging Medication for Metabolic Syndrome and Its Related Diseases. Mol 22(10): 1795.

6. Rezasoltani S, Mojarad EN, Norouzinia M \& Aghdaei HA (2017). The necessity of gut microbiome characterization in diseases prevention and therapy. Gastroenterol Hepatol from bed to bench. pp. 150-151.

7. Moos WH, Faller DV, Harpp DN, Kanara I, Pernokas J, Powers WR \& Steliou K (2016). Microbiota and neurological disorders: a gut feeling. Biol Res Open Access 5(1): 137-145.

8. Scott KP, Gratz SW, Sheridan PO, Flint HJ $\&$ Duncan SH (2013). The influence of diet on the gut microbiota. Pharmacol Res 69(1): 52-60.

9. Hemarajata P \& Versalovic J (2013). Effects of probiotics on gut microbiota: mechanisms of intestinal immunomodulation and neuromodulation. Ther Adv Gastroenterol 6(1): 39-51.

10. Kumar M, Babaei P, Ji B \& Nielsen J (2016). Human gut microbiota and healthy aging: Recent developments and future prospective. Nutr Healthy Aging 4(1): 3-16. 
11. Cordain L, Miller J, Eaton, S, Mann N, Holt S \& Speth J (2000). Plant-animal subsistence ratios and macronutrient energy estimations in worldwide huntergatherer diets. Am J Clin Nutr 71(3): 682692.

12. Hawkes K, O'connell JF \& Jones NGB (1991). Hinting income patterns among the Hadza: Big game, common goods, forging goals and the evolution of the human diet. Philos Trans Biol Sci 334: 243-251.

13. Pendyala S, Walker JM \& Holt PR (2012). A high-fat diet is associated with endotoxemia that originates from the gut. Gastroenterol 142(5): 1100-1101.

14. Turnbaugh P, Ridaura V, Faith J, Rey F, Knight R \& Gordon J (2009). The Effect of Diet on the Human Gut Microbiome: A Metagenomic Analysis in Humanized Gnotobiotic Mice. Sci Transl Med 1(6): 6ra14-6ra14.

15. Davenport E, Mizrahi-Man O, Michelini K, Barreiro L, Ober C \& Gilad Y (2014). Seasonal Variation in Human Gut Microbiome Composition. PloS One 9(3): 90731

16. KAli A (2015). Human microbiome engineering: the future and beyond. $J$ Clin Diagn Res 9(9): DE01.

17. Donia M (2015). A Toolbox for Microbiome Engineering. Cell Syst 1(1): 21-23.

18. Hutkins R, Krumbeck J, Bindels L, Cani P, Fahey G, Goh Y \& et al. (2016). Prebiotics: why definitions matter. Curr Opin Biotechnol 37: 1-7.

19. Macfarlane SMGT, Macfarlane GT and Cummings JT (2006). Prebiotics in the gastrointestinal tract. Aliment Pharmacol Ther 24(5): 701-714.

20. Marteau P \& Seksik P (2004). Tolerance of probiotics and prebiotics. $J$ Clin Gastroenterol 38: 67-69.

21. Foxx-Orenstein AE \& Chey WD (2012). Manipulation of the gut microbiota as a novel treatment strategy for gastrointestinal disorders. Am J Gastroenterol Suppl 1(1): 41.
22. Langdon A, Crook N \& Dantas G (2016). The effects of antibiotics on the microbiome throughout development and alternative approaches for therapeutic modulation. Genome Med 8(1): 39.

23. Kitazawa H, Villena J \& Alvarez S (Eds.). (2013). Probiotics: immunobiotics and immunogenics. CRC Press.

24. Kamada N, Chen GY, Inohara N \& Núñez G (2013). Control of pathogens and pathobionts by the gut microbiota. Nat Immunol 14(7): 685.

25. Kitazawa H, Alvarez S, Suvorov A, Melnikov V, Villena J \& Sánchez B (2015). Recent advances and future perspective in microbiota and probiotics. Biol Med Res Inter.

26. Shah NP (2004). Probiotics and prebiotics. Agro Food Indu Hi Tech 15(1): 13-17.

27. Ma C, Wasti S, Huang S, Zhang Z, Mishra R, Jiang S \& et al. (2020). The gut microbiome stability is altered by probiotic ingestion and improved by the continuous supplementation of galactooligosaccharide. Gut Microbes 12(1): 1785252.

28. Naimi S, Viennois E, Gewirtz A \& Chassaing B (2021). Direct impact of commonly used dietary emulsifiers on human gut microbiota. Microbiome 9(1): 66.

29. Antushevich, H (2020). Fecal microbiota transplantation in disease therapy. Clinica Chimica Acta, 503: 90-98.

30. Scott K.P, Jean-Michel A, Midtvedt T \& van Hemert S (2015). Manipulating the gut microbiota to maintain health and treat disease. Microb Ecol Health Dis 26(1): 25877.

31. Lu TK, Mimee M, Citorik RJ \& Pepper K (2017). Engineering the Microbiome for Human Health Applications. In the Chemistry of Microbiomes: Proceedings of a Seminar Series. NAP (US).

32. Gianotti RJ \& Moss AC (2017). Fecal microbiota transplantation: from Clostridium difficile to inflammatory bowel disease. Gastroenterol Hepatol 13(4): 209. 
33. Jing $\mathrm{Y}, \mathrm{Yu} \mathrm{Y}$, Bai $\mathrm{F}$, Wang L, Yang D, Zhang C \& et al. (2021). Effect of fecal microbiota transplantation on neurological restoration in a spinal cord injury mouse model: involvement of brain-gut axis. Microbiome 9(1): 59.

34. Wilson B, Vatanen T, Jayasinghe T, Leong K, Derraik J, Albert B \& et al. (2021). Strain engraftment competition and functional augmentation in a multi-donor fecal microbiota transplantation trial for obesity. Microbiome 9(1): 107.

35. Foo JL, Ling H, Lee YS \& Chang MW (2017). Microbiome engineering: current applications and its future. Biotechnol $J$ 12(3): 1600099.

36. Rea MC, Dobson A, O'Sullivan O, Crispie F, Fouhy F, Cotter PD, Shanahan F, Kiely B, Hill C, \& Ross RP (2011). Effect of broad- and narrow-spectrum antimicrobials on Clostridium difficile and microbial diversity in a model of the distal colon. Proc Natl Acad Sci USA 108 (Suppl 1): 4639-4644.

37. Francino MP (2016). Antibiotics and the human gut microbiome: dysbioses and accumulation of resistances. Front Microbiol 6: 1543.

38. Strati F, Pujolassos M, Burrello C, Giuffrè M, Lattanzi G, Caprioli F \& et al. (2021). Antibiotic-associated dysbiosis affects the ability of the gut microbiota to control intestinal inflammation upon fecal microbiota transplantation in experimental colitis models. Microbiome 9(1): 39.

39. Lankelma JM (2017). The role of the intestinal microbiota in pneumonia and sepsis. PhD. Thesis. Facult. of Med., Univ. of Amsterdam., Netherlands.

40. De La Cochetière MF, Durand T, Lepage $P$, Bourreille A, Galmiche J. P \& Doré J (2005). Resilience of the dominant human fecal microbiota upon short-course antibiotic challenge. $J$ Clin Microbiol 43(11): 5588-5592.

41. Penders J, Thijs C, van den Brandt PA, Kummeling I, Snijders B, Stelma F, Adams H, van Ree R \& Stobberingh EE (2007). Gut microbiota composition and development of atopic manifestations in infancy: the KOALA Birth Cohort Study. Gut 56(5): 661-667.

42. Jernberg C, Löfmark S, Edlund C \& Jansson JK (2007). Long-term ecological impacts of antibiotic administration on the human intestinal microbiota. The ISME $J$ 1(1): 56-66.

43. Dethlefsen L, Huse S, Sogin ML, \& Relman DA (2008). The pervasive effects of an antibiotic on the human gut microbiota, as revealed by deep $16 \mathrm{~S}$ rRNA sequencing. PLoS Biol 6(11): 280.

44. Jakobsson HE, Jernberg C, Andersson AF, Sjölund-Karlsson M, Jansson JK \& Engstrand L (2010). Short-term antibiotic treatment has differing long-term impacts on the human throat and gut microbiome. PloS One 5(3): 9836.

45. Fouhy F, Guinane CM, Hussey S, Wall R, Ryan CA, Dempsey EM, Murphy B, Ross RP, Fitzgerald GF, Stanton C \& Cotter PD (2012). High-throughput sequencing reveals the incomplete, short-term recovery of infant gut microbiota following parenteral antibiotic treatment with ampicillin and gentamicin. Antimicrobial Agents and Chemotherapy 56(11): 58115820.

46. Panda S, El khader I, Casellas F, López Vivancos J, García Cors M, Santiago A \& et al. (2014) Short-Term Effect of Antibiotics on Human Gut Microbiota. PLoS One 9(4): 95476.

47. Claesen J \& Fischbach MA (2015). Synthetic microbes as drug delivery systems. ACS Synth Biol 4(4): 358-364.

48. Lagenaur LA, Sanders-Beer BE, Brichacek B, Pal R, Liu X, Liu Y, Yu R, Venzon D, Lee PP \& Hamer D. H (2011). Prevention of vaginal SHIV transmission in macaques by a live recombinant Lactobacillus. Mucosal Immunol 4(6): 648-657.

49. Chen Z, Guo L, Zhang Y, Walzem RL, Pendergast JS, Printz RL, Morris LC, Matafonova E, Stien X, Kang L \& Coulon D (2014). Incorporation of therapeutically modified bacteria into gut microbiota 
inhibits obesity. J Clin Invest 124(8): 33913406.

50. Yamamoto S, Wada J, Katayama $\mathrm{T}$, Jikimoto T, Nakamura M, Kinoshita S, Lee KM, Kawabata M \& Shirakawa T (2010). Genetically modified Bifidobacterium displaying Salmonella-antigen protects mice from lethal challenge of Salmonella Typhimurium in a murine typhoid fever model. Vaccine 28(41): 6684-6691.

51. Hernani M, Ferreira PC, Ferreira DM, Miyaji EN, Ho PL \& Oliveira ML (2011). Nasal immunization of mice with Lactobacillus casei expressing the pneumococcal surface protein $\mathrm{C}$ primes the immune system and decreases pneumococcal nasopharyngeal colonization in mice. FEMS Microbiol Immunol 62(3): 263-272.

52. Duan FF, Liu JH \& March JC (2015). Engineered commensal bacteria reprogram intestinal cells into glucose-responsive insulin-secreting cells for the treatment of diabetes. Diabetes 64(5): 1794-1803.

53. Lagenaur LA, Sanders-Beer BE, Brichacek B, Pal R, Liu X, Liu Y, Yu R, Venzon D, Lee PP \& Hamer DH (2011). Prevention of vaginal SHIV transmission in macaques by a live recombinant Lactobacillus. Mucosal Immunol 4(6): 648-657.

54. Duval M, Lewis CJ, Nomellini JF, Horwitz MS, Smit J, \& Cavacini LA (2011). Enhanced neutralization of HIV by antibodies displayed on the S-layer of Caulobacter crescentus. Antimicrob Agents Chemother 55(12): 5547-5552.

55. Vangelista L, Secchi M, Liu X, Bachi A, Ji L, Xu Q, \& Lusso P (2010). Engineering of
Lactobacillus jensenii to secrete RANTES and a CCR5 antagonist analogue as live HIV-1 blockers. Antimicrob Agents Chemother 54(7): 2994-3001.

56. Duan F \& March JC (2010). Engineered bacterial communication prevents Vibrio cholerae virulence in an infant mouse model. Proc Natl Acad Sci USA 107(25): 11260-11264.

57. Ho CL, Tan HQ, Chua KJ, Kang A, Lim KH, Ling KL, Yew WS, Lee YS, Thiery JP \& Chang MW (2018). Engineered commensal microbes for diet-mediated colorectal-cancer chemoprevention. Nat Biomed Eng 2(1): 27-37.

58. Focareta A, Paton JC, Morona R, Cook J \& Paton AW (2006). A recombinant probiotic for treatment and prevention of cholera. Gastroenterol 130(6): 1688-1695.

59. Paton AW, Jennings MP, Morona R, Wang H, Focareta A, Roddam LF \& Paton JC (2005). Recombinant probiotics for treatment and prevention of enterotoxigenic Escherichia coli diarrhea. Gastroenterol 128(5): 1219-1228.

60. Koo OK, Amalaradjou MA, \& Bhunia AK (2012). Recombinant probiotic expressing Listeria adhesion protein attenuates Listeria monocytogenes virulence in vitro. PloS One 7(1): 29277.

61. Sánchez B, López P, González-Rodríguez I, Suárez A, Margolles A \& Urdaci MC (2011). A flagellin-producing Lactococcus strain: interactions with mucin and enteropathogens. FEMS Microbiol Lett 318(2): 101-107. 